\title{
Effects of interfacial oxide layer thickness and interface states on conversion efficiency of $\mathrm{SnO}_{2} / \mathrm{SiO}_{2} / \mathrm{Si}(\mathrm{N})$ solar cells
}

\author{
D. Hocine, MS. Belkaid \\ Faculty of Electrical and Computer Engineering \\ The University Mouloud Mammeri BP 17 RP 15000, Tizi-Ouzou, Algeria \\ Phone: +213 777429 37. Fax:+213 262183 10. e-mail: dalila_mgs2004@yahoo.fr, belkaid_ms@yahoo.fr
}

\begin{abstract}
The interfacial layer in a Schottky barrier solar cell plays an important role in determining the short circuit current, open circuit voltage, fill factor and efficiency of the cell. In this paper, we studied the effects of interfacial oxide layer thickness, interface state density and $\Phi_{0}$ (the level above the valence band to which surface states are filled in isolated semiconductor) on the open circuit voltage and efficiency of the $\mathrm{SnO}_{2} / \mathrm{SiO}_{2} / \mathrm{Si}(\mathrm{N})$ solar cells. From our analysis, we have found that the efficiency of the cell increases at first with the interfacial oxide layer thickness $\delta$, and after acquiring a maximum value falls with a further increase of $\delta$. We have optimized the interfacial layer thickness for maximum efficiency. The solar cell current-voltage characteristics under illumination are also computed for different values of insulator thickness $\delta$. The results obtained by numerical simulation using Matlab programs are presented and discussed. The $\mathrm{SnO}_{2} / \mathrm{SiO}_{2} / \mathrm{Si}(\mathrm{N})$ solar cells, in which the interfacial oxide layer thickness is optimized to $21 \mathrm{~A}^{\circ}$, have an average open circuit voltage of $0.62 \mathrm{~V}$ and a short circuit current of $36 \mathrm{~mA} / \mathrm{cm}^{2}$. The calculated conversion efficiency of the cells can be as high as $17.5 \%$.
\end{abstract}

Keywords: Solar cell, Heterostructure, Oxide layer, Efficiency, Simulation.

\section{Introduction}

There has been considerable interest in recent years directed toward the development of metal-insulatorsemiconductor (MIS) solar cells. Very often in these structures, tin oxide $\left(\mathrm{SnO}_{2}\right)$, indium tin oxide (ITO), and zinc oxide $(\mathrm{ZnO})$ were used in place of the metal electrode [1],[2],[3],[4]. Among these, $\mathrm{SnO}_{2}$ is chosen because of its high electrical conductivity [5],[6],[7],[8],[9] and its transparency in the visible and infrared light [6],[10],[11], therefore it acts as a window for sunlight. Further, its refractive index lies in between 1.9 and 2.0 and hence it can be used as an antireflection (AR) coating [12],[13],[14],[15]. In addition, $\mathrm{SnO}_{2}$ exhibits very good chemical resistance to the majority of chemicals used in the PV industry [2],[16].

In this paper, we consider an heterostructure solar cell $\mathrm{SnO}_{2} / \mathrm{SiO}_{2} / \mathrm{Si}(\mathrm{N})$, in which the interfacial layer $\left(\mathrm{SiO}_{2}\right)$ plays an important role in reducing the dark current leading to the improvement of the open circuit voltage and the efficiency of the cell. We present, here, simulation results using Matlab programs for $\mathrm{SnO}_{2} / \mathrm{SiO}_{2} / \mathrm{Si}(\mathrm{N})$ type solar cells. The effects of interfacial oxide thickness, interface state density and $\Phi_{0}$ (the level above the valence band to which surface states are filled in isolated semiconductor) on the performance of the device have been studied. The interfacial thickness has been optimized to $21 \mathrm{~A}^{\circ}$ for maximum efficiency.

\section{Theory}

Figure 1 shows the basic structure of the device in which a thin insulating layer of $\mathrm{SiO}_{2}$ is sandwiched between tin oxide $\mathrm{SnO}_{2}$ (as the metal) and the monocrystalline N-type silicon. Electrodes are put on the front and back surface, the top electrode being a grid structure.

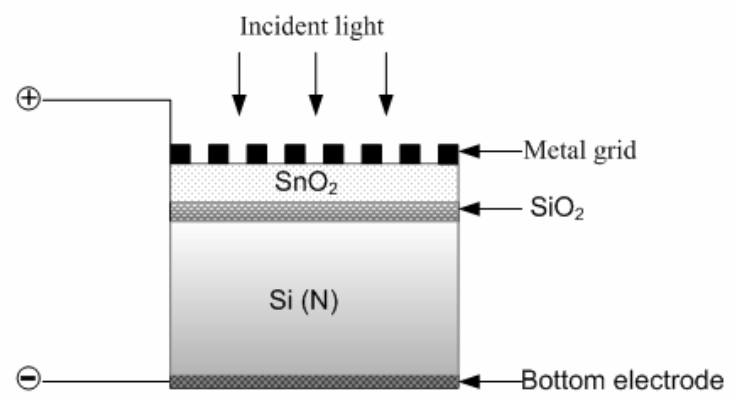

Figure 1. Schematic diagram of $\mathrm{SnO}_{2} / \mathrm{SiO}_{2} / \mathrm{Si}(\mathrm{N})$ solar cell 
In these devices, the space charge electric field used to separate the hole-electron pairs is generated by the workfunction difference between the metal and the semiconductor. The equilibrium band diagram for $\mathrm{SnO}_{2} / \mathrm{SiO}_{2} / \mathrm{Si}(\mathrm{N})$ system is shown in figure 2. In MIS type devices, the interfacial oxide layer and the interface states can strongly affect the magnitude of barrier height. This is expressed (neglecting image-force reduction) as [17]:

$$
\Phi_{B n}=\gamma \Phi_{B 0}+(1-\gamma)\left(E_{g}-\Phi_{0}\right)
$$

where

$$
\begin{gathered}
\Phi_{B 0}=\Phi_{m}-\chi \\
\gamma=(1+\alpha)^{-1} \\
\alpha=\frac{q}{\varepsilon_{0}}\left(\frac{D_{S}}{K_{i}}\right) \delta
\end{gathered}
$$

where $\Phi_{\mathrm{m}}$ is the metal work function, $\mathrm{E}_{\mathrm{g}}$ is the band gap of silicon, $\chi$ is the electron affinity of silicon, $\delta$ is the thickness of the interfacial oxide layer $\left(\mathrm{SiO}_{2}\right), \mathrm{D}_{\mathrm{S}}$ is the interface state density, $\mathrm{K}_{\mathrm{i}}$ is the relative dielectric constant of $\mathrm{SiO}_{2}$ and $\Phi_{\mathrm{Bn}}$ is the Schottky barrier height for N-type device.

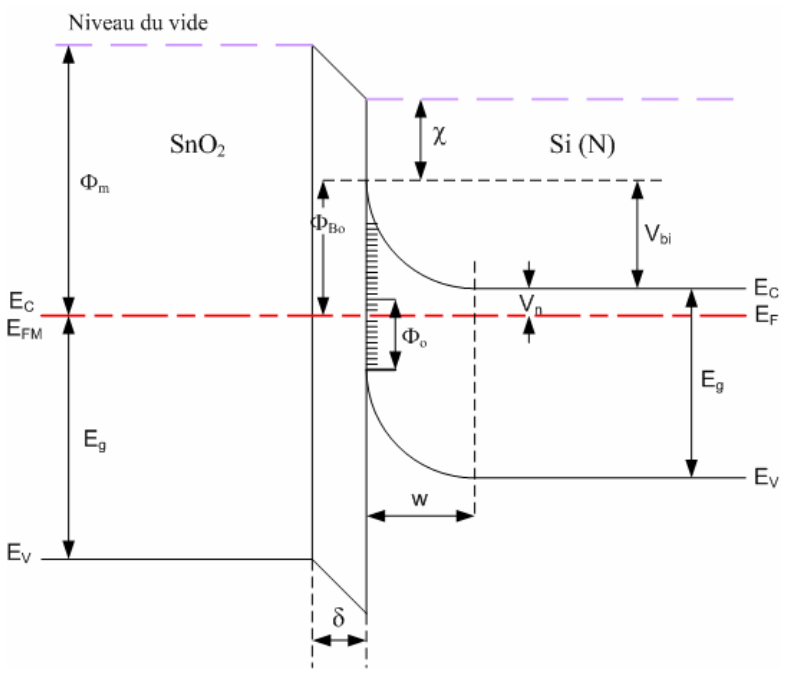

Figure 2. Energy band diagram for $\mathrm{SnO}_{2} / \mathrm{SiO}_{2} / \mathrm{Si}(\mathrm{N})$ solar cell under equilibrium

Illuminating the MIS solar cell results in a voltage "V" across the cell, a part $\mathrm{V}_{\mathrm{i}}$ appears across the interfacial layer of thickness $\delta$, while the rest $V_{S}$ appears across the depletion region of width "W" of the semiconductor. Thus

$$
V=V_{i}+V_{S}
$$

The energy band diagram for $\mathrm{SnO}_{2} / \mathrm{SiO}_{2} / \mathrm{Si}(\mathrm{N})$ system under illumination is shown in figure 3.

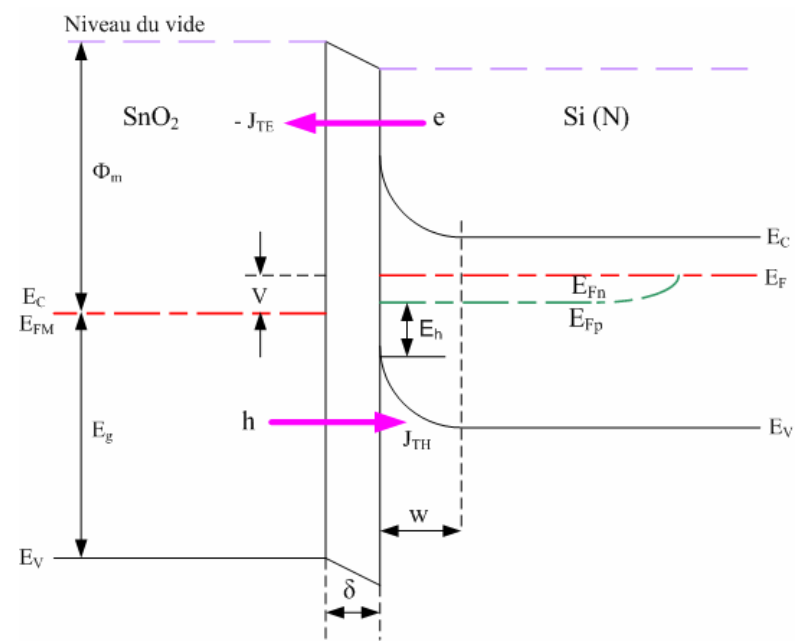

Figure 3. Energy band diagram for $\mathrm{SnO}_{2} / \mathrm{SiO}_{2} / \mathrm{Si}(\mathrm{N})$ solar cell under illumination

The photovoltage (V) developed leads to a net current density $(\mathrm{J})$ which is given by:

$$
J=J_{T H}-J_{T E}
$$

where

$\mathrm{J}_{\mathrm{TH}}$ is the hole tunnelling current from the semiconductor to the metal, $\mathrm{J}_{\mathrm{TE}}$ represents the electrons tunnelling current from the semiconductor to the metal. This is expressed as [18]:

with

$$
J_{T E}=J_{S}\left[\exp \left(\frac{q V_{S}}{K T}\right)-1\right]
$$

$$
J_{S}=A^{*} T^{2} \exp \left[\frac{-q \cdot \Phi_{B n}}{K T}\right] \exp \left[-\chi^{1 / 2} \delta\right]
$$

In equation (8), $\chi$ and $\delta$ are in units of $\mathrm{eV}$ and $\mathrm{A}^{\circ}$ respectively. $\mathrm{A}^{*}$ is the Richardson's constant, $\mathrm{T}$ is the temperature and $\mathrm{K}$ is the Boltzmann's constant.

The solar cell current-voltage characteristic developed under illumination is given by J.P Singh [17] as:

$$
J=J_{p h}-J_{0}\left[\exp \left(\frac{q\left(\Delta+V_{S}\right)}{K T}\right)-1\right]-J_{S}\left[\exp \left(\frac{q \cdot V_{S}}{K T}\right)-1\right]
$$


Where

$$
J_{0}=\frac{P_{n o} \cdot q \cdot D_{p}}{L_{p}}
$$

and

$$
\begin{gathered}
J_{p h}=q . \Phi\left[1-\frac{\exp \left(-\alpha^{\prime} w\right)}{1+\alpha^{\prime} L_{p}}\right] \\
\Delta=E_{g}-\Phi_{B n}-E_{h}
\end{gathered}
$$

In the above equations, $\mathrm{J}_{\mathrm{ph}}$ is the photogenerated current, $\mathrm{J}_{\mathrm{S}}$ and $\mathrm{J}_{0}$ are saturation and diffusion (holes) currents respectively, $\mathrm{E}_{\mathrm{h}}$ is the minority carrier (hole) quasi-Fermilevel from the valence band at the surface $\left(E_{h} \geq 0.085 \mathrm{eV}\right.$ for $\left.\mathrm{N}_{\mathrm{D}}=10^{18} \mathrm{~cm}^{-3}\right)$. $\mathrm{P}_{\mathrm{no}}$ is the illuminated hole concentration far away from the junction, $D_{p}$ is the diffusion coefficient for holes, $\mathrm{L}_{\mathrm{p}}$ is the diffusion length, $\alpha^{\prime}$ is the absorption coefficient of the material and $\Phi$ is the light flux density.

\section{Results and discussion}

\section{A. Effect of the interface state density on the Schottky barrier height}

The calculated Schottky barrier heights are shown schematically in figure 4 . This demonstrates the sensitivity of Schottky barrier height to the interface state density for different values of $\Phi_{0}$. We see that when $\Phi_{0}$ is set equal to $0.3 \mathrm{eV}, \Phi_{\mathrm{Bn}}$ becomes independent of the interface state density $\mathrm{D}_{\mathrm{S}}$. When $\Phi_{0}>0.3 \mathrm{eV}, \Phi_{\mathrm{Bn}}$ will decrease whereas for $\Phi_{0}<0.3 \mathrm{eV}, \Phi_{\mathrm{Bn}}$ will increase with increase of $\mathrm{D}_{\mathrm{S}}$.

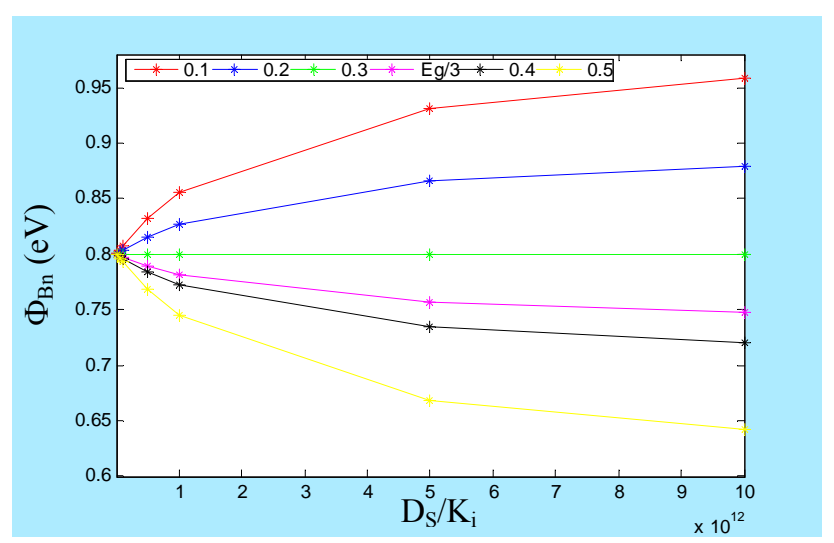

Figure 4. Variation of $\Phi_{\mathrm{Bn}}$ with interface state density at different values of $\Phi_{0}$ under optimum conditions.

\section{B. Effect of the interfacial oxide layer thickness on the} open circuit voltage of the $\mathrm{SnO}_{2} / \mathrm{SiO}_{2} / \mathrm{Si}(\mathrm{N})$ solar cells

The results of calculation of open circuit voltage $V_{\text {oc }}$ as a function of $\delta$ for different values of $\Phi_{0}$ are shown schematically in figure 5 . These calculations have been done for the following two cases.

- Case 1: $\Phi_{0}=0.1 \mathrm{eV}, D_{S} / K_{i}=5 \times 10^{12} \mathrm{~cm}^{-2} \mathrm{eV}^{-1}$

- Case 2: $\Phi_{0}=\mathrm{E}_{\mathrm{g}} / 3 \mathrm{eV}, D_{S} / K_{i}=10^{10} \mathrm{~cm}^{-2} \mathrm{eV}^{-1}$

The open circuit voltage is determined by the photogenerated current $J_{p h}$ and the reverse current $J_{S}$ as given in equation (13):

$$
V_{o c}=\frac{K T}{q} \operatorname{Ln}\left(\frac{J_{p h}}{J_{S}}+1\right)
$$

The increase in open circuit voltage with increasing the interfacial layer thickness $\delta$ in the initial stages is due to reverse current $\left(\mathrm{J}_{\mathrm{S}}\right)$ reduction. This can be explained as follows: an increase in the interfacial oxide layer thickness $\delta$ results in a decrease in transmission of electrons across the interfacial layer and in the increased potential $V_{i}$ appearing across the interfacial layer. This increase in $V_{i}$ leads to an increase of the effective barrier height $\Phi_{\text {Bn }}^{*}(=$ $\Phi_{\mathrm{Bn}}+\mathrm{V}_{\mathrm{i}}$ ) which hinders the flow of majority carriers. These two factors play a role in reducing the reverse current $J_{S}$ and hence the thermionic emission current $\mathrm{J}_{\mathrm{TE}}$ which is shown in figure 6.

From equation (13), we see that a smaller $\mathrm{J}_{\mathrm{S}}$ gives a larger $\mathrm{V}_{\text {oc }}$. Beyond a certain $\delta$, the $\mathrm{V}_{\text {oc }}$ decreases, because for higher values of $\delta$ the photogenerated current also decreases [18].

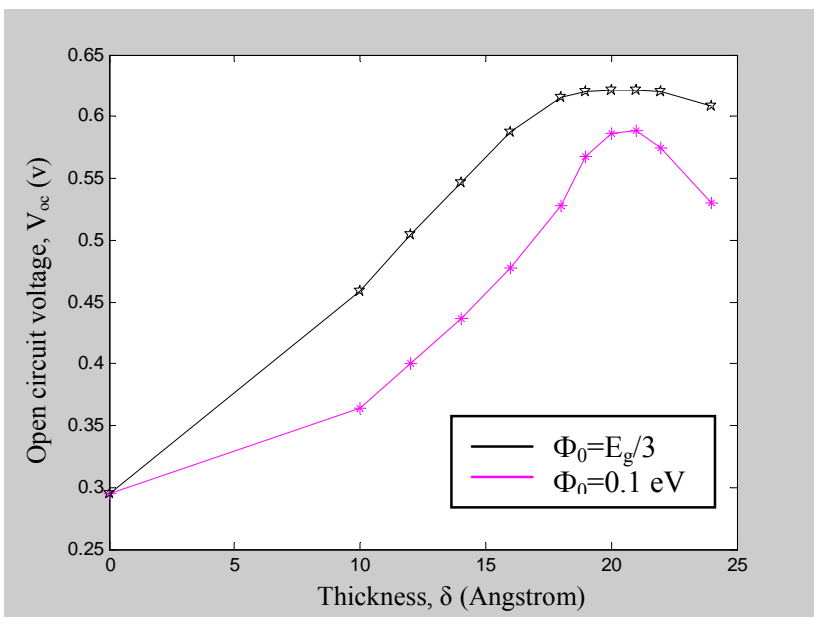

Figure 5. Variations of $\mathrm{V}_{\mathrm{oc}}$ with interfacial oxide layer thickness $\delta$ at different values of $\Phi_{0}$ 


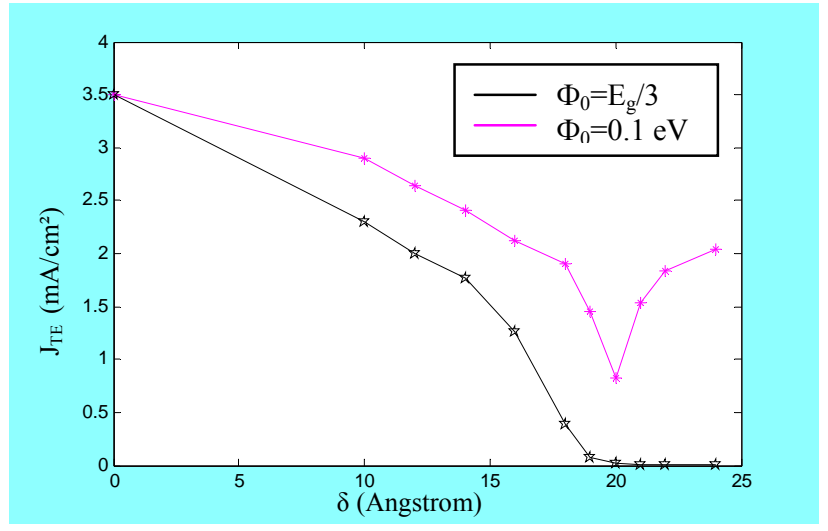

Figure 6. Variations of the thermionic emission current $\mathrm{J}_{\mathrm{TE}}$ with interfacial oxide layer thickness $\delta$ at different values of $\Phi_{0}$

\section{Photovoltaic characteristics of $\mathrm{SnO}_{2} / \mathrm{SiO}_{2} / \mathrm{Si}(\mathrm{N})$ solar cell}

The current-voltage characteristics of the cell under illumination are computed for different values of interfacial oxide (insulator) thickness $\delta$ and presented in figure 7 .

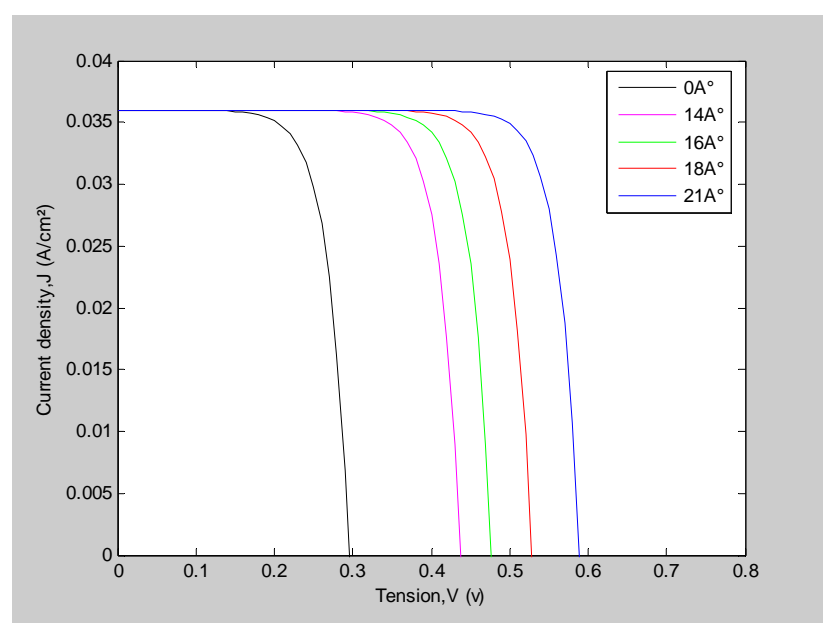

Figure 7. Illuminated $\mathrm{J}-\mathrm{V}$ characteristics for the $\mathrm{SnO}_{2} / \mathrm{SiO}_{2} / \mathrm{Si}(\mathrm{N})$ solar cell at different values of insulator thickness $\delta$ when $\Phi_{0}=0.1 \mathrm{eV}$ under optimum conditions.

It is clear from this figure that the presence of an interfacial oxide layer significantly improves the power characteristics of the cell. In all cases, the short circuit current was not affected by oxide layer inclusion. Its value practically remains constant at $36 \mathrm{~mA} / \mathrm{cm}^{2}$.

\section{Effect of the interfacial oxide layer thickness on the efficiency of the $\mathrm{SnO}_{2} / \mathrm{SiO}_{2} / \mathrm{Si}(\mathrm{N})$ solar cells}

The conversion efficiency of a photovoltaic device is given by:

$$
\eta=\frac{J_{S C} \cdot V_{O C}}{P_{i}} F F
$$

where $\mathrm{P}_{\mathrm{i}}$ is the incident power and FF is the fill factor.

The results of calculation of conversion efficiency of the cell for different values of the interfacial layer thickness for specific values of interface state density and $\Phi_{0}$ are shown in figure 8.

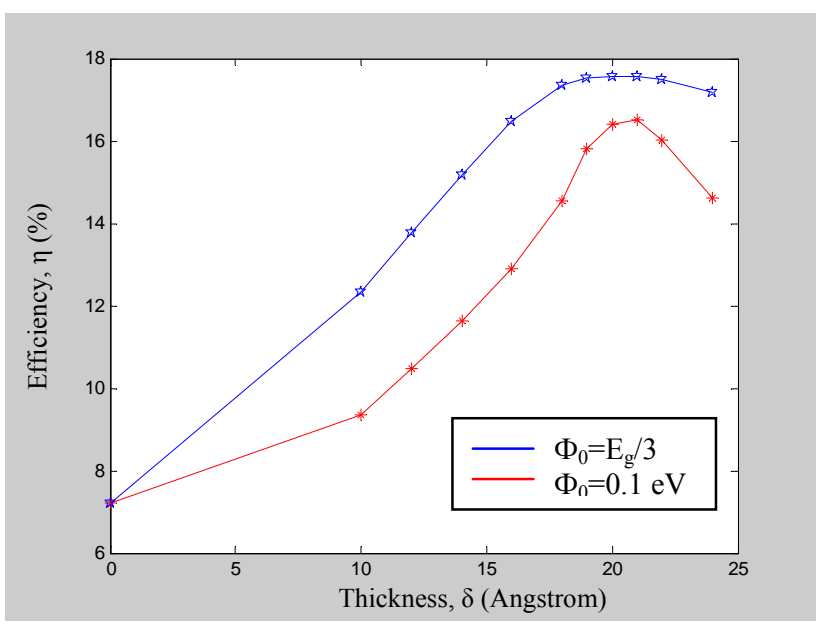

Figure 8. Variations of the efficiency with interfacial oxide layer thickness $\delta$ at different values of $\Phi_{0}$

The efficiency initially increases with $\delta$ due to an increase in open circuit voltage $\mathrm{V}_{\text {oc }}$. When $\Phi_{0}=0.1 \mathrm{eV}$, the decrease in efficiency, after a certain optimum, is mainly due to a decrease in the fill factor FF for higher values of $\delta$ according to equation (14). In Table 1 we give the calculated values for fill factor FF for two cases: $\Phi_{0}=0.1$ $\mathrm{eV}$ and $\Phi_{0}=\mathrm{E}_{\mathrm{g}} / 3 \mathrm{eV}$.

From figures 5 and 8, it is apparent that for both $\Phi_{0}=0.1$ $\mathrm{eV}$ and $\Phi_{0}=\mathrm{E}_{\mathrm{g}} / 3 \mathrm{eV}$; maximum values for open circuit voltage and efficiency are obtained at $21 \mathrm{~A}^{\circ}$. 
TABLE 1: The calculated values for fill factor FF for different values of the interfacial oxide layer thickness $\delta$ for specific values of $\Phi_{0}$, under optimum conditions.

\begin{tabular}{|c|c|c|}
\hline $\begin{array}{c}\delta \\
\left(\mathrm{A}^{\circ}\right)\end{array}$ & $\begin{array}{c}\mathrm{FF} \\
\left(\Phi_{0}=0.1 \mathrm{eV}\right)\end{array}$ & $\begin{array}{c}\mathrm{FF} \\
\left(\Phi_{0}=\mathrm{E}_{\mathrm{g}} / 3 \mathrm{eV}\right)\end{array}$ \\
\hline 0 & 0.68 & 0.68 \\
\hline 10 & 0.71 & 0.75 \\
\hline 12 & 0.73 & 0.76 \\
\hline 14 & 0.74 & 0.77 \\
\hline 16 & 0.75 & 0.78 \\
\hline 18 & 0.76 & 0.78 \\
\hline 19 & 0.77 & 0.78 \\
\hline 20 & 0.78 & 0.78 \\
\hline 21 & 0.78 & 0.78 \\
\hline 22 & 0.77 & 0.78 \\
\hline 24 & 0.76 & 0.78 \\
\hline
\end{tabular}

The improved fill factor and the increase in the solar conversion efficiency of the cells make such optimized oxide layers, important components in the solar cells fabrication. The $\mathrm{SnO}_{2} / \mathrm{SiO}_{2} / \mathrm{Si}(\mathrm{N})$ type solar cells can be made by a low cost processing like APCVD (Atmospheric pressure chemical vapour deposition) or Spray pyrolysis [2]. These cells can be used in the fabrication of solar panels as clean energy converters.

\section{Conclusion}

The inclusion of an interfacial oxide layer $\left(\mathrm{SiO}_{2}\right)$ between $\mathrm{SnO}_{2}$ and $\mathrm{Si}$ leads to the improvement of the open circuit voltage and efficiency of the solar cells by reducing the dark current. Such improvement allows the use of the $\mathrm{SnO}_{2} / \mathrm{SiO}_{2} / \mathrm{Si}(\mathrm{N})$ type solar cells as clean, efficient and economical energy converters. The optimum oxide layer thickness for maximum efficiency is found to be $21 \mathrm{~A}^{\circ}$. The calculated efficiencies of the cells can be as high as $17.5 \%$.

Combining the high-efficiency, lower cost processing, we believe the $\mathrm{SnO}_{2} / \mathrm{SiO}_{2} / \mathrm{Si}(\mathrm{N})$ type solar cells have good potential to meet the goal of large-scale terrestrial applications.

\section{References}

[1] C.G. Granqvist, A. Hultaker, "Transparent and conducting ITO films: new developments and applications", Thin Solid Films 411 (2002) 1.

[2] R. Tala-Ighil, M. Boumaour, and M.S. Belkaid, "High temperature annealing under air on properties of the thin films of tin oxide doped by Fluorine, deposited by Spray Pyrolysis", Solar Energy Materials and Solar Cells, 2006, pp. $1-18$.

[3] M. Batzill, U. Diebold, "The surface and materials science of tin oxide", Progress in Surface Science, Vol. 79, 2005.

[4] B.G. Lewis, D.C. Paine, "Applications and processing of transparent conducting oxides”, MRS Bull. 25 (2000) 22.
[5] M.S Belkaid, K. Lagha, "Characterization of Physical Properties of $\mathrm{SnO}_{2}$ thin films Annealed at High Temperature Deposited by APCVD”, 22 nd European Photovoltaic Solar Energy Conference, Milan, Italy, September 2007.

[6] C. Kilic, A. Zunger, "Origins of coexistence of conductivity and transparency in $\mathrm{SnO}_{2}$ ", Phys. Rev. Lett. 88 (2002) 095501.

[7] Y. Matsui, Y.Yamamoto and S. Takeda, "Stability in Electrical Properties of Ultra Thin Tin Oxide Films", Materials Research Society, Vol. 621, 2000.

[8] T.J. Coutts, D.L. Young, X. Li, MRS Bull. 25 (2000) 58.

[9] Y.S Choe, J.H Chung, D.S Kim, "Phase Transformation and Morphological Evolution of Ion-Beam Sputtered Tin Oxide Films on Silicon Substrate", Materials Research Bulletin, Vol. 34, N9, 1999.

[10] D.S. Ginley, C. Bright, "Transparent conducting oxides", MRS Bull. 25 (2000) 15.

[11] A.M.B. Van Mol, "Chemical Vapour Deposition of Tin Oxide Thin Films", doctorate thesis, Eindhoven University, 2003.

[12] Y. Mi, H. Odaka, S. Iwata, "Electronic structures and optical properties of $\mathrm{ZnO}, \mathrm{SnO}_{2}$ and $\mathrm{In}_{2} \mathrm{O}_{3}$ ”, Jpn. J. Appl. Phys. 38 (1999) 3453.

[13] G. Jain, R. Kumar, "Electrical and optical properties of tin oxide and antimony doped tin oxide films", Opt. Mater. 26 (2004) 27.

[14] M.-M. Bagheri-Mohagheghi, M. Shokooh-Saremi, "The influence of $\mathrm{Al}$ doping on the electrical, optical and structural properties of $\mathrm{SnO}_{2}$ transparent conducting films deposited by the spray pyrolysis technique", J. Phys. D: Appl. Phys. 37 (2004) 1248.

[15] T. Minami, MRS Bull. 25 (2000) 38.

[16] R. Gordon, "Criteria for choosing transparent conductors", MRS. Bull. 25 (2000) 52.

[17] J.P. Singh, R.S. Srivastava, "Efficiency of $\mathrm{SnO}_{2} / \mathrm{Si}$ solar cells", Indian Journal of Pure and Applied Physics, Vol. 20, February 1982, pp. 104- 110.

[18] A.K. Ghosh, C. Fishman, and T. Feng, " $\mathrm{SnO}_{2} / \mathrm{Si}$ Solar CellsHeterostructure or Schottky-barrier or MIS-Type Device", J. Appl. Phys, Vol. 49, №6, June 1978. 